\title{
Developing a Neural Networks Model for Evaluating Financial Performance of Residential Companies based on FCM
}

\author{
Mohamed Elsadek $^{1}$, Hany Abd Elshakour ${ }^{2}$ and Ahmed Elyamany ${ }^{3}$ \\ 1M.Sc. Student, Construction Engineering \& Utilizes Department, Faculty of Engineering, Zagazig University, \\ Egypt. \\ 2Associate Professor, Construction Engineering \& Utilizes Department, Faculty of Engineering, Zagazig \\ University, Egypt. \\ 3 Assistant Professor, Construction Engineering \& Utilizes Department, Faculty of Engineering, Zagazig \\ University, Egypt.
}

\begin{abstract}
Intense competition among construction companies urges for continuous improvement and evaluation of performance. Many researches recognized the importance of financial performance (FP) and attempted to develop a reliable model to evaluate the company FP. The main objective of this research is developing an accurate model to evaluate the financial performance of residential construction companies. Financial data of a number of residential construction companies were collected from the Egyptian Authority of Money Market in the form of balance sheets and income statement. The most six ratios affecting company financial performance were identified and calculated. Every financial point (case) defined with six financial ratios. The financial ratios represent the model input while the model output, i.e. performance index, is developed using fuzzy c-mean clustering (FCM). Artificial Neural Network (ANN) is utilized to develop the relation between the input and output variables. Some points were kept for the purpose of testing the validity of the developed model. The validation of the model showed satisfactory results which provide a sufficientdegree of reliability to use the model in evaluating the financial performance of construction companies.
\end{abstract}

Keywords: Financial performance ; Residential construction companies; Financial ratios; Fuzzy clustering; Fuzzy C-means; Artificial neural network.

\section{INTRODUCTION}

Companies in the residential construction sector, like others in the industry sectors, seek to improve their performance. That's because performance evaluation is a valuable tool to assist leaders, managers, and members of the organization in developing the direction, traction and speed of their organization (Adkins, 2006). Nowadays, the performance indicators include not only financial indicators but also nonfinancial indicators, such as market share, innovation, and customer satisfaction. The performance measurement from the financial perspective was recognized as being the most important criterion in many researches. On the other hand, the construction industry in worldwide suffers from the largest number of bankruptcies of any sector of the economy, with the highest number of companies failing because of poor financial management (Farghaly 2010). Many studies and researches have been conducted since the early 1990's to develop frameworks that can be used to measure the company's performance (AbdElshakour et al. 2013). Although the concepts of performance measurement are developed to improve the performance of construction companies, it can sometimes mislead management. If it is not accurate or is not appropriately designed and implemented for the construction organization, it can be of no use and sometimes become a threat for the business.Many mathematical techniques have been used to evaluate the performance. The most common techniques are; regression analysis, and discriminate analysis, simulation, and ANN. Also, many researchers have developed models to evaluate FP for construction companies using ANN, i.e. Goda (1999), Farghaly (2010), and Mohamad (2014), but most of these models lack representing the model output in a reliable and accurate way. So, the main problem is to find an accurate method to express the performance index to be used as an input variable in the process of developing the model. However; until now (and according to my knowledge) there is no any study in Egypt used fuzzy with the neural network to build a modelwhich makes results more accurate. In this research a combination between fuzzy theory and ANN has been done toincrease the reliability and accuracy of results.There are two main objectives of this research, first one is applying fuzzy clustering technique (FCM) to categorize the financial points into two clusters, the financial performance index is represented by the membership value for the better cluster. The second objective is using (ANN) technique to model the relation between the input" financial ratios" and output "the financial performance".

The methodology of this research comprises several steps as illustrated in figure (1): 


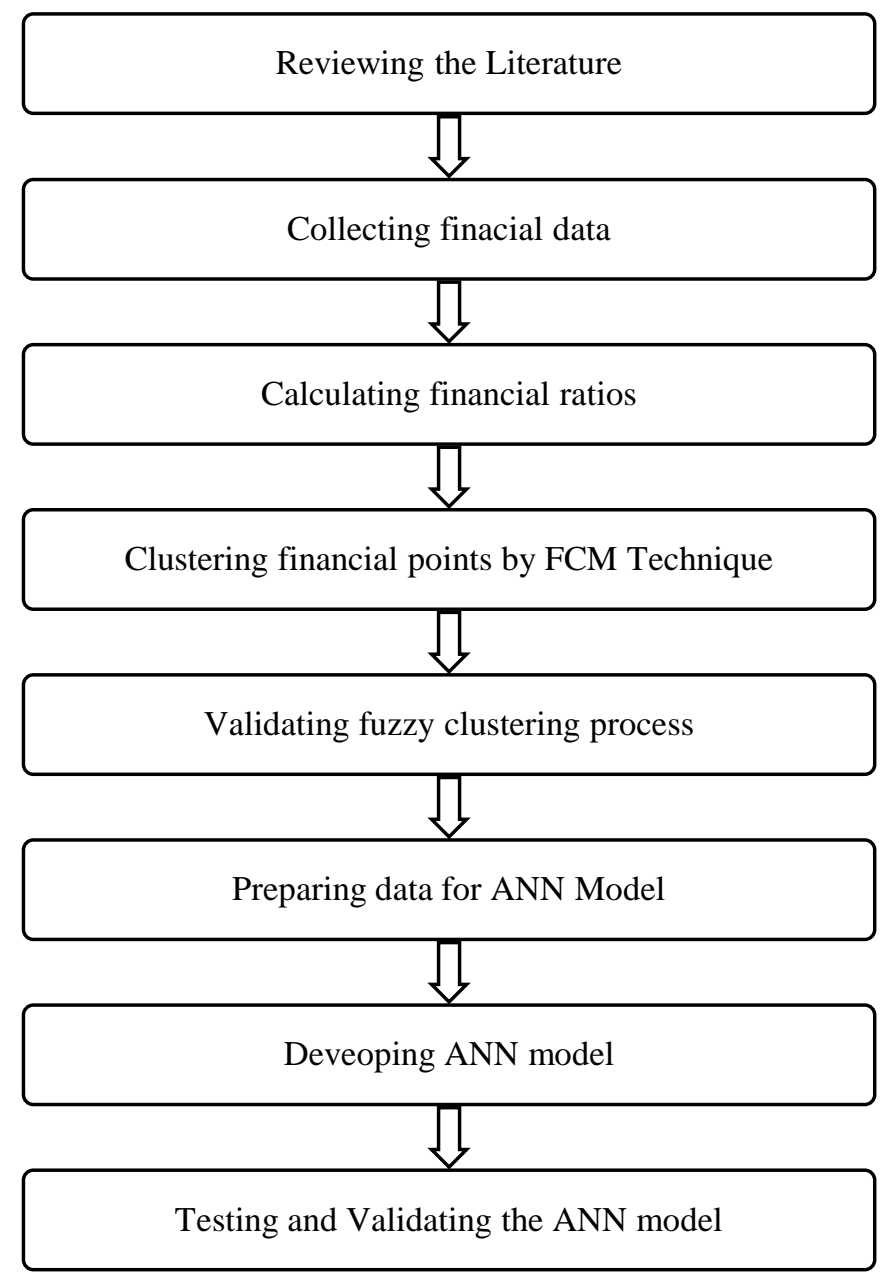

Figure (1): Illustration of study methodology

\section{FINANCIAL RATIOS}

Financial ratios are originally used to evaluate the performance of construction companies.Financial data for construction companies are presented in financial statements which keep financial information about a company. There are two main financial statements, balance sheet and income statement. In financial statements, numbers that appear in both income statement and balance sheet are seem tobe insignificant because they did not tell the reader any information about the real company position among other companies (Elyamany, 2005). Financial ratios are designed to evaluate financial statement. Ratio analysis is the most widely technique used in analyzing financial data. Also, financial ratios provide important information for both investors and analysts to identify the position and the productivity of the companies within the industries for specific period of time (Gallizo\& Salvador, 2003). According to Haplin (1985), Newton (1994)and other references, financial ratios are divided into 4 main categories; Liquidity ratios, Debt ratios, Activity ratios, and Profitability ratios.

\section{Performance Evaluation Models Using FinanCial Ratios}

Many studies developed models to evaluate the FP of construction companies, most of which used financial ratios to express the FP for companies. Beaver (1968) conducted the first modern statistical evaluation model to predict financial failure. The model introduced a sophisticated statistical technique for direct analysis of an unlimited number of cases in which ratios were calculated from fund's statement data. Altman (1968) developed a model known as Z-score model to differentiate between failed and non-failed companies. The Zscore is a weighted average of several ratios that assesses balance sheet strength and FP. Edmisteer (1972) developed a model using zero-one linear regression to determine the probability of failure on a sample of small business companies. For the first time, Fillipone (1976) introduced a study relevant to construction industry. Fillipone model categorize companies into failed or non-failed. Moyer (1977) re-examined Altman's bankruptcy model. He used a stepwise multiple discriminate analysis model that eliminated the market value of equity/book value of total debt and sales/total assets ratio. Russell and Zhai (1996) model considered both financial and 
economic variables in the development of their model. Goda (1999) developed a model to evaluate the FP of construction companies using both regression analysis and ANN. Elyamany (2005) updated Goda (1999) model using regression analysis and considered macro-economic and industry related factors in the developed model Elyamany (2005). Farghaly (2010) developed an ANN model to predict the financial performance and concluded that using ANN is more effective in predicting the FP with error less than 13\%. Tehrani (2012) developed a model to evaluate corporate performance through Data Envelopment Analysis to rank companies in two steps. Yalcin (2012) structured a hierarchical. FP model based on the Accounting-based Financial Performance and Value-based Financial Performance main-criteria and their sub-criteria. Yalcin (2012) model used Fuzzy Analytic Hierarchy Process to determine the weights of the criteria. Abdul Halim et al. (2012) examined the role of financial management in the success or failure of construction firms. The findings of the study revealed that construction companies have insufficient cash capital to finance their work, low profit margins from construction projects and are highly dependent on debt to finance construction costs. The lack of monitoring systems for companies' cash flow and project costs were the main causes of failure.

\section{MODELLING TECHNIQUES}

Many models had been developed to evaluate FP for construction companies using different modeling techniques such Artificial Neural network (ANN), Fuzzy logic (FL), and a combination of both which called Neurofuzzy (NF). The following section discusses in brief each of the previous modeling techniques

\section{ARTIFICIAL NeURAL NETWORK (ANN)}

ANNs are introduced as hardware or software systems analogous to biological neural systems both in structure and in functionality (Moselhi et al. 1991). Zayed and Halpin (2005) defined ANN as "the process of developing the ability to generalize, which correctly classify new patterns or to make forecasts and predictions". Back Propagation Neural Networks are one of the most common ANN algorithms. Back propagation algorithms are especially capable to solve problems of prediction makes them highly popular (Maulenkamp and Grima 1999).In most cases a neural network is an adaptive system changing its structure during a learning phase. Neural Networks (NN) are used for modeling complex relationships between inputs and outputs or to find patterns in data. An ANN is typically defined by three types of parameters as shown figure (2) (Nitin kumara et al 2013):

1-The interconnection pattern between different layers of neurons.

2-The learning process for updating the weights of the interconnections.

3-The activation function that converts a neuron's weighted input to its output activation.

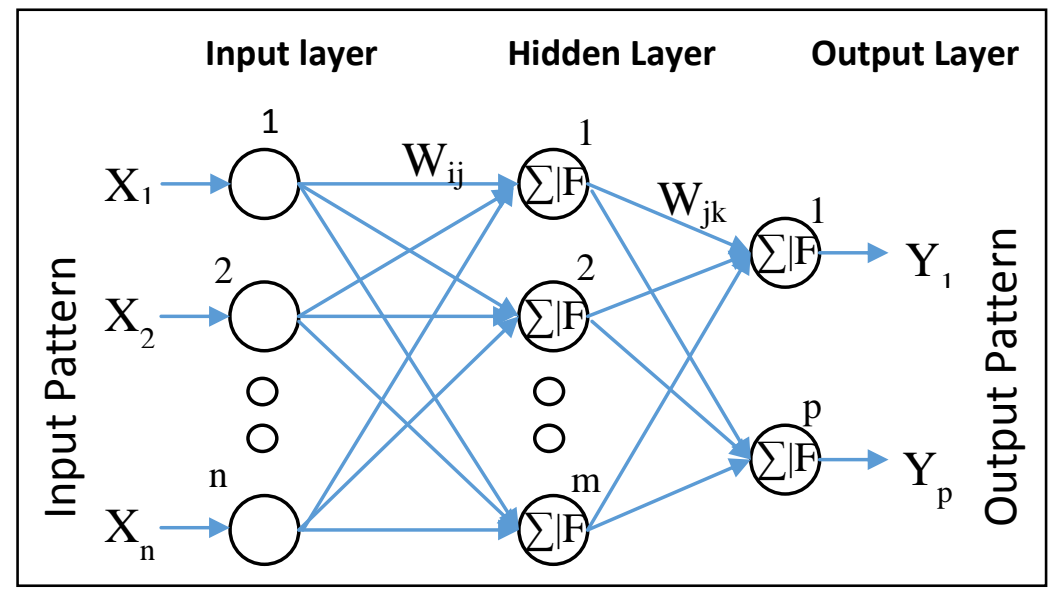

Figure (2): typical three-layer network architecture

ANN has some advantages include (Nitin kumara et al 2013):

- Adaptive learning: An ability to learn how to do tasks based on the data given for training or initial experience.

- Self-Organization: An ANN can create its own organization or representation of the information it receives during learning time.

- Real Time Operation: ANN computations may be carried out in parallel, and special hardware devices are being designed and manufactured which take advantage of this capability.

Also,ANN has some disadvantages include (Nitin kumara et al 2013):

- ANN can be used only if training data is available. It is not necessary to have a mathematical model of the problem of interest, and there is no need to provide any form of prior knowledge.

DOI: 10.9790/1684-1402024659 www.iosrjournals.org 48 | Page 
- The solution obtained from the learning process usually cannot be interpreted.

- Most neural network architectures are black boxes. They cannot be checked whether their solution is plausible, i.e. their final state cannot be interpreted in terms of rules.

- A neural network usually cannot be initialized with prior knowledge if it is available, and thus the network must learn from scratch.

- The learning process itself can take very long, and there is usually no guarantee of success.

Applications of ANNs in construction management go back to the early 1990s. These applications cover many critical topics in productivity, quality, time estimation, bidding, performance evaluation. [Moselhi et al. (1991); Boussabaine and Kaka (1998); Kim et al. (2004b); Jain et al. (2008)].

\section{FUZZY LOGIC (FL)}

Fuzzy logic is an effective tool that can be used for modelling complex systems (Mendel ,2001). It has become popular in the modeling of different systems, Lotfizadeh developed fuzzy logic in the mid-1960s to solve the problem of representing approximate knowledge that cannot be represented by conventional, crisp methods. Lotfizadeh defined fuzzy logic as "a class of objects with a continuum of grades of membership". It is similar to human thinking and interpretation and gives meaning to expressions like "often", "smaller" and "higher".Any "element" value in the universe of field of the fuzzy set will have a grade of membership which gives the degree to which the particular element belongs to the set (Karray and de Silva, 2004). Generally, Fuzzy logic respects five steps. Firstly, input membership functions (MFs) are assigned to input characteristics. Secondly, the membership functions are linked to rules. Thirdly, the rules are connected to output characteristics and then output membership functions are assigned to the output characteristics. Finally, a one-valued output is concluded from the output membership functions (Ross, 2009). Fuzzy logic has several advantages which make it a powerful technique for modeling and control problems, (Lee, 2006) stated some of these advantages:

1-It does not require precise inputs and the output control is a smooth control function in spite of the broad

2 -variations of the inputs.

3-Fuzzy logic is not limited to a certain number of inputs and outputs.

4-It saves time when compared to conventional mathematical methods.

5-It is easily adjusted by simply changing the rules.

6-It can deal with information that would be difficult or impossible to model mathematically.

Although Fuzzy Logic has many advantages over conventional mathematical methods, some limitations are inherent to fuzzy logic such as (Lee, 2006):

1-It lacks self-organizing and self-tuning mechanisms.

2-The knowledge base rules definition and the fuzzy system quickly becomes complex when too many inputs and outputs are used in developing a fuzzy model.

3-Lot of data are required and expertise to develop a fuzzy system.

\section{NEUROFUZZY (NF)}

Each intelligent system has particular computational abilities (e.g. ability to learn, explanation of decisions) that make it suitable for particular problems and not for others. For example, while artificial neural networks are good at recognizing patterns, they are not good at clarifying how they get their decisions. Fuzzy logic systems, which can deal with fuzzy and imprecise data, are good at explaining their decisions but they cannot automatically acquire the rules they use to make those decisions. These limitations have been a central driving force behind the creation of intelligent hybrid systems where two or more techniques are combined in a manner that overcomes the limitations of individual techniques. (Fuller, 1995).So, each one of these techniques has advantages and disadvantages that, when mixed together, their cooperation provides better results than the ones achieved with the use of each lonely technique.Neurofuzzy technique is a combination of ANN and FL. Among the advantages of NF (Zaptron, 1999); (1) handles any kind of information, (2) manages imprecise, partial, vague or imperfect information, (3) resolves conflicts by collaboration and aggregation, self-learning, self-organizing and self-tuning capabilities, (4) no need of prior knowledge of relationships of data, (5) mimics human decision-making process and (6) fast computation using fuzzy number operations.Many studies have been done using of NF in the research area of construction management over the past few years. Boussabaine (2001) developed NF model to determine the duration of construction project. Lam et al. (2001) developed a NF model to improve the objectiveness of contractor prequalification. Liu and Ling (2003) developed NF model to help contractors estimate markup percentage to be included in their tenders. Mahmoud (2014) developed a NF model based to predict the horizontal directional drilling. Georgy et al. (2005) presents a NF study to predict the engineering performance in a construction project. Jin, X. (2010) developed a NF model to assist in the decision-making of Public Private Partnership projects. Rashidi (2011) provides NF model to select a project manager. Thippara (2012) developed a NF model to evaluate the construction sustainability of highway design 
projects in Thailand. Also, the combination of Artificial Neural Networks (ANN) and Fuzzy Systems (FS) have attracted the interest of other researchers in various engineering and scientific areas due to the need of adaptive intelligent systems to solve the real world problems. (Dagbui et al 2013) [ Parvizsedghy (2015), Zayed (2014), Dagbui et al (2013), Tokede and Wamuziri (2012), Rashidi (2011), Jin, X. (2010), Marzouk and Moselhi (2004)].

\section{Cluster ANAlysis}

Clustering is one of the well-known techniques with successful dealing with high-dimensional data. The main purpose of data clustering is to collect data points that are similar (homogenous) to each other in groups (or clusters). Dividing the data set based on the assumption that the sets belonging to the same cluster are as similar as possible, whereas sets belonging to different clusters are as dissimilar as possible (Alwakil, 2011). Data clustering is a common technique for statistical data analysis, which is used in many fields, including machine learning, data mining, image analysis and bioinformatics. Also, clustering is used to discover relevance knowledge in data. It is considered a powerful tool for model construction. It identifies the natural groupings in data from a large data set, which allows concise representation of relationships hidden in the data (Bataineh, 2011). Cluster analysis has been used in many studies, such as estimating haulers, travel time for estimating earthmoving production (Marzouk and Moselhi, 2004).

\section{CluSTER TECHNIQUES}

There are two main approaches for clustering data the first approach is crisp clustering (hard clustering) and the other one is fuzzy clustering. The crisp (hard) clustering method restrict that each point of the data set belonging completely to just only one cluster, that's mean an object either does or does not belong to a cluster, the membership value exactly equal 0 or 1.Fuzzy clustering is one of well-known unsupervised clustering techniques which allows one piece of data belongs to two or more clusters The main benefit of fuzzy clustering is to assign a probability of inclusion. It allows gradual memberships of data points to clusters measured as degrees in $[0,1]$. Figure 3 shows the difference between hard and fuzzy clustering.

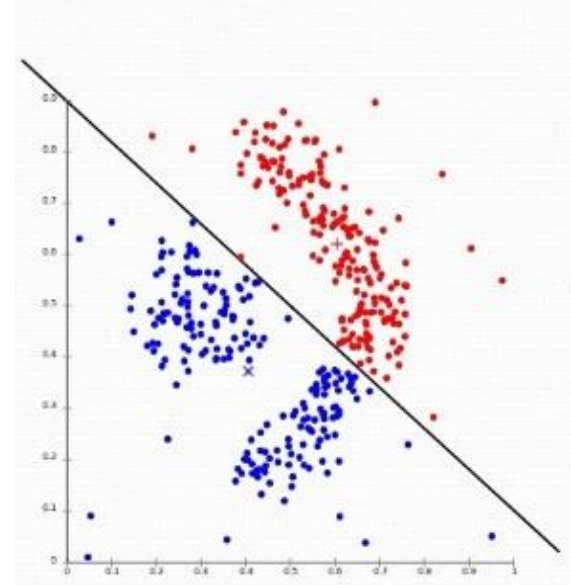

Figure (3) Hard clustering

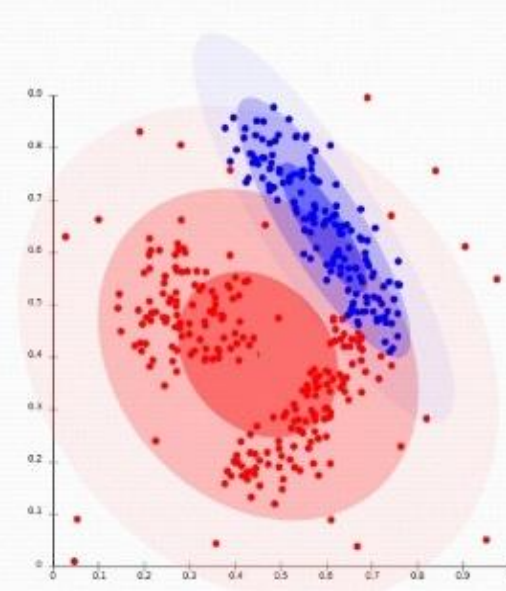

Fuzzy clustering

\section{FCM ALgORITHM}

Generally, Fuzzy logic respects five steps. Firstly, input membership functions (MFs) are assigned to input characteristics. Secondly, the membership functions are linked to rules. Thirdly, the rules are connected to output characteristics and then output membership functions are assigned to the output characteristics. Finally, a one-valued output is concluded from the output membership functions (Ross, 2009). The FCM algorithm is one of the most popular clustering methods based on minimization of a generalized least-squared errors function. This method was developed by Dunn (1973) and improved by Bezdek (1981). As mentioned before, fuzzy clustering algorithms give the membership values between 0 and 1 which indicate the degree of membership for each element to each group. The algorithm of FCM is based on minimization of the following objective function

$J=\sum_{i=1}^{N} \sum_{j=1}^{C} \mu_{i j}\left|X_{i}-C_{j}\right|^{2}$

Where;

uij is the probability of membership of the element $i$ to the jth cluster;

xi the ith element; 
$\mathrm{Cj}$ the coordinates of the jth center of the cluster;

| | represents the Euclid norm;

$\mathrm{N}$ he number of elements in the database;

$\mathrm{C}$ refers to the total number of clusters considered.

Fuzzy partitioning is implemented by an iterative optimization of the objective function with the update of membership uij and the cluster centers $\mathrm{Cj}$, by:

$u_{i j}=\frac{1}{\sum_{k_{k-1}}^{C}\left(\frac{\left|x_{i}-C_{j}\right|}{\left|x_{i}-C_{k}\right|}\right)^{2}}$

$c_{j}=\frac{\sum_{i=1}^{n}\left(\mu_{i j}\right)^{m} x_{i}}{\sum_{i=1}^{n}\left(\mu_{i j}\right)^{m}}$

Equation (2) clearly shows the probabilistic membership degree. It depends not only on the distance of the object xi to the cluster $\mathrm{Cj}$, but also on the distances between this object and other clusters.

\section{MODEL DEVELOPMENT}

The process of developing the model will consist of steps shown in Figure 4. As stated before, the main objective of this study is developing an accurate FP model by combining the ANN and fuzzy logic which increase the reliability and accuracy for the results. The general form of model is presented in equation (4):

$\mathrm{PI}=\sum_{\mathrm{i}=1}^{6} \mathrm{a}_{\mathrm{i}} \mathrm{x}_{\mathrm{i}}$

Where:

PI = dependent variable represents company Performance Index.

ai $=$ Variable coefficients,

$\mathrm{xi}=$ independent variable represented by Financial ratios.

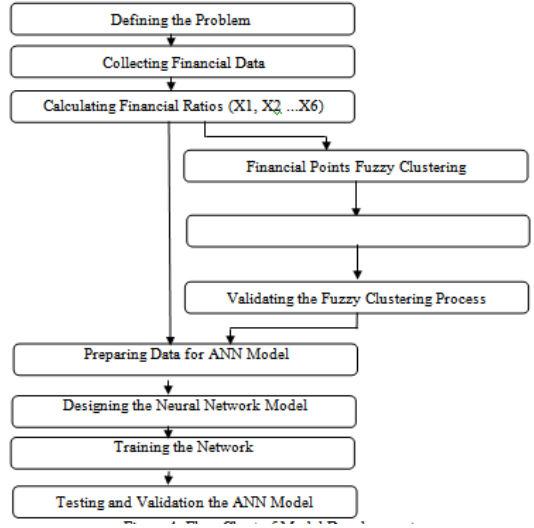

Figure 4: Flow Chart of Model Development

\section{Defining The Problem}

As cleared before, many previous efforts have aimed to develop a model for evaluating company financial performance. Many of these models are developed using neural network or regression. Some of them are criticized for their inaccuracy. So, the main problem involves in developing an Appropriate and accurate financial performance model depending on a combination between fuzzy c-mean and ANN to direct and control construction organization.

\section{XiII. Data Collection\& Preparation}

Financial data for residential construction companies were collected -in the form of annual sheets and income statements - from the Authority of Money Market for the time period 2000-2011.This period was chosen because the construction industry in Egypt at this period was stable quite the opposite in the period after 2011 due to the political events. The study will be applied on $8 \$$ financial statements for 15 residential companies.Table (1) shows sample of financial data extracted from fintncial statements and income sheets. 
Table 1: Sample of financial data

\begin{tabular}{|c|c|c|c|c|c|c|c|c|c|}
\hline $\begin{array}{c}\text { Case } \\
\text { No. }\end{array}$ & $\begin{array}{l}\text { Curren } \\
\text { t Assets }\end{array}$ & $\begin{array}{c}\text { Current } \\
\text { Liabilitie } \\
\mathrm{s}\end{array}$ & $\begin{array}{c}\text { Total } \\
\text { Liabiliti } \\
\text { es }\end{array}$ & $\begin{array}{c}\text { Net } \\
\text { Worth }\end{array}$ & $\begin{array}{l}\text { Fixed } \\
\text { Assets }\end{array}$ & $\begin{array}{c}\text { Revenue } \\
\text { S }\end{array}$ & $\begin{array}{c}\text { Worki } \\
\text { ng } \\
\text { Capita } \\
\text { l }\end{array}$ & $\begin{array}{l}\text { Net } \\
\text { Profit }\end{array}$ & $\begin{array}{c}\text { Total } \\
\text { Assets }\end{array}$ \\
\hline 1 & 22 & $\begin{array}{r}1910 \\
4\end{array}$ & $\begin{array}{r}2030 \\
7\end{array}$ & $\begin{array}{c}20982 \\
89\end{array}$ & 4 & $\begin{array}{c}099196 \\
7\end{array}$ & $\begin{array}{c}151573 \\
08\end{array}$ & $\begin{array}{c}76022 \\
2\end{array}$ & $\begin{array}{c}3013 \\
6\end{array}$ \\
\hline 2 & $\begin{array}{l}33043 \\
98\end{array}$ & $\begin{array}{c}3676398 \\
1\end{array}$ & $\begin{array}{c}3688398 \\
4\end{array}$ & \begin{tabular}{|c|}
213933 \\
62
\end{tabular} & $\begin{array}{c}497294 \\
8\end{array}$ & 9819260 & $\begin{array}{c}165404 \\
17\end{array}$ & $\begin{array}{c}780059 \\
8\end{array}$ & $\begin{array}{c}5827734 \\
6\end{array}$ \\
\hline 3 & $\begin{array}{c}544487 \\
05\end{array}$ & $\begin{array}{c}3761850 \\
3\end{array}$ & $\begin{array}{c}3773850 \\
5\end{array}$ & $\begin{array}{c}217868 \\
40\end{array}$ & $\begin{array}{c}507664 \\
0\end{array}$ & $\begin{array}{c}1368442 \\
1\end{array}$ & $\begin{array}{c}168302 \\
02\end{array}$ & $\begin{array}{c}764332 \\
1\end{array}$ & $\begin{array}{c}5952534 \\
5\end{array}$ \\
\hline 4 & $\begin{array}{l}04651 \\
28\end{array}$ & $\begin{array}{c}4324839 \\
7\end{array}$ & $\begin{array}{c}4336839 \\
9\end{array}$ & $\begin{array}{c}222374 \\
30\end{array}$ & $\begin{array}{c}514070 \\
2\end{array}$ & $\begin{array}{c}1279966 \\
5\end{array}$ & $\begin{array}{c}172167 \\
30\end{array}$ & $\begin{array}{c}898205 \\
1\end{array}$ & $\begin{array}{c}6560583 \\
0\end{array}$ \\
\hline 5 & $\begin{array}{c}19726 \\
87\end{array}$ & $\begin{array}{c}4342786 \\
7\end{array}$ & $\begin{array}{c}4354786 \\
9\end{array}$ & \begin{tabular}{|c|}
237173 \\
19
\end{tabular} & $\begin{array}{c}529250 \\
2\end{array}$ & $\begin{array}{c}1617847 \\
3\end{array}$ & $\begin{array}{c}185448 \\
19\end{array}$ & $\begin{array}{c}913060 \\
2\end{array}$ & $\begin{array}{c}6726518 \\
9\end{array}$ \\
\hline 6 & $\begin{array}{c}39392 \\
56\end{array}$ & $\begin{array}{c}5291763 \\
8\end{array}$ & $\begin{array}{c}303764 \\
0\end{array}$ & $\begin{array}{c}265782 \\
61\end{array}$ & \begin{tabular}{|c|}
567664 \\
6
\end{tabular} & $\begin{array}{c}1673564 \\
7\end{array}$ & $\begin{array}{c}210216 \\
17\end{array}$ & $\begin{array}{c}111745 \\
68\end{array}$ & $\begin{array}{c}7961590 \\
2\end{array}$ \\
\hline 7 & $\begin{array}{c}67279 \\
03\end{array}$ & $\begin{array}{c}4722949 \\
5\end{array}$ & $\begin{array}{c}734949 \\
7\end{array}$ & $\begin{array}{c}356132 \\
79\end{array}$ & $\begin{array}{c}623489 \\
4\end{array}$ & $\begin{array}{c}1588049 \\
1\end{array}$ & $\begin{array}{c}294984 \\
07\end{array}$ & $\begin{array}{c}118593 \\
34\end{array}$ & $\begin{array}{c}8296279 \\
7\end{array}$ \\
\hline 8 & \begin{tabular}{|c|}
100491 \\
630
\end{tabular} & $\begin{array}{c}6101675 \\
7\end{array}$ & $\begin{array}{c}6113675 \\
9\end{array}$ & $\begin{array}{c}456410 \\
66\end{array}$ & $\begin{array}{c}628619 \\
5\end{array}$ & $\begin{array}{c}2340536 \\
5\end{array}$ & \begin{tabular}{|c|}
394748 \\
73
\end{tabular} & \begin{tabular}{|c|}
152124 \\
59
\end{tabular} & $\begin{array}{c}1067778 \\
25\end{array}$ \\
\hline 9 & $\begin{array}{c}122367 \\
191\end{array}$ & $\begin{array}{c}7057940 \\
5\end{array}$ & $\begin{array}{c}7069940 \\
8\end{array}$ & $\begin{array}{c}583615 \\
40\end{array}$ & $\begin{array}{c}669375 \\
7\end{array}$ & $\begin{array}{c}2238248 \\
9\end{array}$ & \begin{tabular}{|c|}
517877 \\
86
\end{tabular} & \begin{tabular}{|c|}
164173 \\
08
\end{tabular} & $\begin{array}{c}1290609 \\
48\end{array}$ \\
\hline 10 & $\begin{array}{c}158152 \\
961\end{array}$ & $\begin{array}{c}8995354 \\
1\end{array}$ & $\begin{array}{c}9007354 \\
4\end{array}$ & \begin{tabular}{|c|}
723470 \\
86
\end{tabular} & $\begin{array}{c}426766 \\
8\end{array}$ & $\begin{array}{c}3198659 \\
0\end{array}$ & \begin{tabular}{|c|}
681994 \\
20 \\
\end{tabular} & \begin{tabular}{|c|}
236604 \\
52
\end{tabular} & $\begin{array}{l}624206 \\
29\end{array}$ \\
\hline
\end{tabular}

\section{XIV. $\quad$ Financial Ratios Calculation}

As stated before, financial ratios are divided into 4 main categories; Liquidity ratios, Debt ratios, Activity ratios, and Profitability ratios.Each of these groups has a large number of ratios, not all the ratios have the same importance. This fact helps to reduce the number of ratios concluded in the model only to six ratios. Financial ratios used in developing the model are those considered significant to the company performance. Also ratios selected to represent the four main ratios categories(Halpin, 1985; Dun \&Bradstreet, 2001):

Current Ratio (CR): equals Current Assets divided by Current Liabilities. It measures the degree to which current assets cover current liabilities. A ratio of 2 or higher is desirable.

Total Debt to Net Worth Ratio (TD/NW): shows how all of the company's debt to the equity of the owner or stockholders. Higher ratio means less protection for creditors.

Fixed Assets to Net Worth (FA/NW): shows the percentage of assets centered in fixed assets compared to total equity.

Revenues to Working Capital ratio (RV/WC): measures the number of times working capital turns over annually in relation to net sales.

Net Profit to Total Assets (NP/TA): considered the key indicator of profitability.

Net Profit to Net Worth (NP/NW): measures the ability of a company's management to realize an adequate return on the capital investment.

The independent variables in equation (1) represented by financial ratio as follow:

$\mathrm{x} 1=\mathrm{CR}$,

$\mathrm{x} 2=\mathrm{TD} / \mathrm{NW}$,

$\mathrm{x} 3=\mathrm{FA} / \mathrm{NW}$,

$\mathrm{x} 4=\mathrm{RV} / \mathrm{WC}$,

$\mathrm{x} 5=\mathrm{NP} / \mathrm{TA}$, and

$\mathrm{x} 6=\mathrm{NP} / \mathrm{NW}$.

Financial ratios were calculated using previously stated formula based up on the collected financial data. Table (2) shows a sample of financial ratios values.

Table 2: Sample of financial ratios.

\begin{tabular}{|c|c|c|c|c|c|c|}
\hline $\begin{array}{c}\text { Point } \\
\text { no. }\end{array}$ & CR & TD/NW & FA/NW & RV/WC & NP/TA & NP/NW \\
\hline $\mathbf{1}$ & 1.362 & 2.003 & 0.283 & 0.725 & 0.139 & 0.418 \\
\hline $\mathbf{2}$ & 1.450 & 1.724 & 0.232 & 0.594 & 0.134 & 0.365 \\
\hline
\end{tabular}




\begin{tabular}{|c|c|c|c|c|c|c|}
\hline $\mathbf{3}$ & 1.447 & 1.732 & 0.233 & 0.813 & 0.128 & 0.351 \\
\hline $\mathbf{4}$ & 1.398 & 1.950 & 0.231 & 0.743 & 0.137 & 0.404 \\
\hline $\mathbf{5}$ & 1.427 & 1.836 & 0.223 & 0.872 & 0.136 & 0.385 \\
\hline $\mathbf{6}$ & 1.397 & 1.996 & 0.214 & 0.796 & 0.140 & 0.420 \\
\hline $\mathbf{7}$ & 1.625 & 1.330 & 0.175 & 0.538 & 0.143 & 0.333 \\
\hline $\mathbf{8}$ & 1.647 & 1.340 & 0.138 & 0.593 & 0.142 & 0.333 \\
\hline $\mathbf{9}$ & 1.734 & 1.211 & 0.115 & 0.432 & 0.127 & 0.281 \\
\hline $\mathbf{1 0}$ & 1.758 & 1.245 & 0.059 & 0.469 & 0.146 & 0.327 \\
\hline
\end{tabular}

The next step is using fuzzy cluster $\mathrm{C}$-mean technique to categorize the financial points into two clusters. Depending on the center of every cluster and the relation between the financial ratios and the performance index, the better cluster will be determined. The performance index will represent by the membership value of the better cluster.

\section{Financial Points Clustering By FCM}

The Performance Index (PI) in equation (4) is attained using fuzzy clustering for the chosen data to form the FP model. Fuzzy clustering generalizes partition clustering methods (such as C-means) by allowing the partial membership which means a member to be partially classified into more than one cluster. In fuzzy clustering, the membership is spread among all clusters. The probability that object $\mathrm{i}$ is classified into cluster $\mathrm{k}$ can now be between zero and one, with the stipulation that the sum of their values is equal to 1 . It has the advantage that it does not force every object into a specific cluster. It has the disadvantage that there is much more information to be interpreted (NCSS V9 help). The financial data points are categorized into two clusters in order to make it as simple and applicable as possible to use by construction companies' practitioners. The analysis process considered the performance pattern between clusters center as if it is an arithmetic mean to avoid the complex formulation of matrices more than two clusters are considered. Algorithmic steps for Fuzzy c-means clustering are as follows:

1) Let $X$ be the set of data points and $V$ the set of centers,

Where; $X=\left\{x_{1}, x_{2}, x_{3}, x_{4}, x_{5}, x_{6}\right\}$ and $V=\left\{v_{1}, v_{2}\right\}$.

2) Randomly select 'c' cluster centers. In the current model $\mathrm{C}=2$.

3) Calculate the fuzzy membership for each point $\mu_{\mathrm{ij}}$ using equation (5):

$\mu_{\mathrm{ij}}=1 / \sum_{\mathrm{k}=1}^{\mathrm{c}}\left(\mathrm{d}_{\mathrm{ij}} / \mathrm{d}_{\mathrm{ik}}\right)^{\left(\frac{2}{\mathrm{~m}}-1\right)}$

Where;

$\mathrm{d}_{\mathrm{ij}}=$ represents the Euclidean distance between $\mathrm{i}^{\text {th }}$ data and $\mathrm{j}^{\text {th }}$ cluster center.

$\mathrm{m}=$ is the fuzziness index $\mathrm{m} €[1, \infty]$.

4) Compute the fuzzy centers $v_{j}$ using equation (6):

$\mathrm{v}_{\mathrm{j}}=\frac{\sum_{\mathrm{i}=1}^{\mathrm{n}}\left(\mu_{\mathrm{ij}}\right)^{\mathrm{m}} \mathrm{x}_{\mathrm{i}}}{\sum_{\mathrm{i}=1}^{\mathrm{n}}\left(\mu_{\mathrm{ij}}\right)^{\mathrm{m}}}, \forall_{\mathrm{j}}=1,2, \ldots \mathrm{c}$

5) Repeat step 2 and 3 until the minimum $\mathrm{j}$ value is achieved or $\|\mathrm{U}(\mathrm{k}+1)-\mathrm{U}(\mathrm{k})\|<\beta$.

Where: $\mathrm{k}$ is the iteration step, $\beta$ is the termination criterion between $[0,1]$,

$\mathrm{U}=(\mu \mathrm{ij}) \mathrm{n} * \mathrm{c}$ is the fuzzy membership matrix, and $\mathrm{j}$ is the objective function.

Sample results of the fuzzy clustering process are shown in Table 3. Each point has a partial membership in both cluster (C1) and cluster (C2). The Centers of clusters C1, C2 are shown in Table 4.

Table 3: Sample results of fuzzy clustering process

\begin{tabular}{|c|c|c|}
\hline point no. & Membership to Cluster 1 (C1) & Membership to cluster 2 (C2) \\
\hline $\mathbf{1}$ & 0.854 & 0.146 \\
\hline $\mathbf{2}$ & 0.8457 & 0.1543 \\
\hline $\mathbf{3}$ & 0.8615 & 0.1385 \\
\hline $\mathbf{4}$ & 0.8532 & 0.1468 \\
\hline $\mathbf{5}$ & 0.858 & 0.142 \\
\hline $\mathbf{6}$ & 0.8478 & 0.1522 \\
\hline $\mathbf{7}$ & 0.8079 & 0.1921 \\
\hline $\mathbf{8}$ & 0.8071 & 0.1929 \\
\hline $\mathbf{9}$ & 0.7681 & 0.2319 \\
\hline $\mathbf{1 0}$ & 0.7828 & 0.2172 \\
\hline
\end{tabular}


Table 4: Value of cluster centers for Six financial ratios

\begin{tabular}{|c|c|c|c|c|c|c|}
\hline Ratio & CR & TD\NW & FA【NW & RV\WC & NP\TA & NP/NW \\
\hline C1 & 2.3405 & 2.4564 & 2.3405 & 2.4564 & 2.3405 & 2.4564 \\
\hline C2 & 2.7683 & 1.9045 & 2.7683 & 1.9045 & 2.7683 & 1.9045 \\
\hline
\end{tabular}

According to the definition of these ratios, It's notice that all ratios are proportional with company financial performance. The higher the ratio, the higher financial performance. Except the (TD/NW) Ratio which inversely proportional with financial performance index (FPI), the higher this ratio, the less protection there is for creditors.According to the relation between financial ratios and performance and the clusters centers, Cluster (C1) reflects a better performance than cluster (C2). So, the financial performance represented by the membership value to the better cluster (C1).

\section{Validation Of Fuzzy Clustering Process}

Testing the validity of the fuzzy clustering process is essentially the same as training it, except that the program is shown points it has never seen before, and no corrections are made. It is important to evaluate the performance of the program after the training process. If the results are good, the PI values will be ready to use. If not this needs more or better data or redesigns. A part offinancial points, i.e. 16 financial pointsare set aside randomlyfrom total points for the purpose of testing the validity of the Fuzzy clustering process. Table (5) presents the actual and predicted membership value of the validation sample. The maximum absolute error between the actual and predicted values is 0.135 and its acceptable error that can be considered as a good indication regarding the validity of the proposed FCM clustering process. Also, the results of testing the FCM clustering process indicated a testing root mean square error (RMSE) of value 0.0762 (7.6\%). Therefor the fuzzy clustering process is passed successfully.

Table (5) actual and predicted membership value

\begin{tabular}{|c|c|c|c|}
\hline $\begin{array}{c}\text { Financial data } \\
\text { point }\end{array}$ & Actual membership & Predicted membership & Absolute Error \\
\hline $\mathbf{1}$ & 0.043 & 0.091 & 0.048 \\
\hline $\mathbf{2}$ & 0.052 & 0.1098 & 0.0578 \\
\hline $\mathbf{3}$ & 0.086 & 0.1853 & 0.0993 \\
\hline $\mathbf{4}$ & 0.134 & 0.269 & 0.135 \\
\hline $\mathbf{5}$ & 0.115 & 0.2213 & 0.1063 \\
\hline $\mathbf{6}$ & 0.185 & 0.2374 & 0.0524 \\
\hline $\mathbf{7}$ & 0.064 & 0.1163 & 0.0523 \\
\hline $\mathbf{8}$ & 0.14 & 0.173 & 0.033 \\
\hline $\mathbf{9}$ & 0.034 & 0.1126 & 0.0786 \\
\hline $\mathbf{1 0}$ & 0.004 & 0.0666 & 0.0626 \\
\hline $\mathbf{1 1}$ & 0.118 & 0.2319 & 0.1139 \\
\hline $\mathbf{1 2}$ & 0.191 & 0.2489 & 0.0579 \\
\hline $\mathbf{1 3}$ & 0.302 & 0.343 & 0.041 \\
\hline $\mathbf{1 4}$ & 0.279 & 0.3243 & 0.0453 \\
\hline $\mathbf{1 5}$ & 0.019 & 0.1209 & 0.1019 \\
\hline $\mathbf{1 6}$ & 0.01 & 0.0395 & 0.0295 \\
\hline
\end{tabular}

XVII. Data Preparing To The anns Model

After finishing the first step of developing the model and testing the validity of FCM process, data will have prepared to model the relation between financial ratios and financial performance index by using the artificial neural networks as showed in table (6).

Table (6) prepared data for the artificial neural network.

\begin{tabular}{|c|c|c|c|c|c|c|c|}
\hline \multirow{2}{*}{ points } & \multicolumn{6}{|c|}{ Inputs } & \multirow{2}{*}{$\begin{array}{c}\text { outputs } \\
\text { P.I \% }\end{array}$} \\
\hline & R1 & $\mathbf{R 2}$ & R3 & R4 & R5 & R6 & \\
\hline 1 & $\begin{array}{c}1.361 \\
7\end{array}$ & $\begin{array}{c}2.003 \\
1\end{array}$ & $\begin{array}{c}0.283 \\
3\end{array}$ & $\begin{array}{c}0.725 \\
2\end{array}$ & $\begin{array}{c}0.139 \\
0\end{array}$ & $\begin{array}{c}0.417 \\
5\end{array}$ & 85.4 \\
\hline 2 & $\begin{array}{c}1.449 \\
9\end{array}$ & $\begin{array}{c}1.724 \\
1\end{array}$ & $\begin{array}{c}0.232 \\
5\end{array}$ & $\begin{array}{c}0.593 \\
7\end{array}$ & $\begin{array}{c}0.133 \\
9\end{array}$ & $\begin{array}{c}0.364 \\
6\end{array}$ & 84.57 \\
\hline 3 & $\begin{array}{c}1.447 \\
4\end{array}$ & $\begin{array}{c}1.732 \\
2\end{array}$ & $\begin{array}{c}0.233 \\
0\end{array}$ & $\begin{array}{c}0.813 \\
1\end{array}$ & $\begin{array}{c}0.128 \\
4\end{array}$ & $\begin{array}{c}0.350 \\
8\end{array}$ & 86.15 \\
\hline 4 & $\begin{array}{c}1.398 \\
1\end{array}$ & $\begin{array}{c}1.950 \\
2\end{array}$ & $\begin{array}{c}0.231 \\
2\end{array}$ & $\begin{array}{c}0.743 \\
4\end{array}$ & $\begin{array}{c}0.136 \\
9\end{array}$ & $\begin{array}{c}0.403 \\
9\end{array}$ & 85.32 \\
\hline 5 & $\begin{array}{c}1.427 \\
0\end{array}$ & $\begin{array}{c}1.836 \\
1\end{array}$ & $\begin{array}{c}0.223 \\
1\end{array}$ & $\begin{array}{c}0.872 \\
4\end{array}$ & $\begin{array}{c}0.135 \\
7\end{array}$ & $\begin{array}{c}0.385 \\
0\end{array}$ & 85.8 \\
\hline 6 & $\begin{array}{c}1.397 \\
3\end{array}$ & $\begin{array}{c}1.995 \\
5\end{array}$ & $\begin{array}{c}0.213 \\
6\end{array}$ & $\begin{array}{c}0.796 \\
1\end{array}$ & $\begin{array}{c}0.140 \\
4\end{array}$ & $\begin{array}{c}0.420 \\
4\end{array}$ & 84.78 \\
\hline 7 & $\begin{array}{c}1.624 \\
6\end{array}$ & $\begin{array}{c}1.329 \\
5\end{array}$ & $\begin{array}{c}0.175 \\
1\end{array}$ & $\begin{array}{c}0.538 \\
4\end{array}$ & $\begin{array}{c}0.142 \\
9\end{array}$ & $\begin{array}{c}0.333 \\
0\end{array}$ & 80.79 \\
\hline
\end{tabular}




\begin{tabular}{|c|c|c|c|c|c|c|c|}
\hline $\mathbf{8}$ & $\begin{array}{c}1.647 \\
0\end{array}$ & $\begin{array}{c}1.339 \\
5\end{array}$ & $\begin{array}{c}0.137 \\
7\end{array}$ & $\begin{array}{c}0.592 \\
9\end{array}$ & $\begin{array}{c}0.142 \\
5\end{array}$ & $\begin{array}{c}0.333 \\
3\end{array}$ & 80.71 \\
\hline $\mathbf{9}$ & $\begin{array}{c}1.733 \\
8\end{array}$ & $\begin{array}{c}1.211 \\
4\end{array}$ & $\begin{array}{c}0.114 \\
7\end{array}$ & $\begin{array}{c}0.432 \\
2\end{array}$ & $\begin{array}{c}0.127 \\
2\end{array}$ & $\begin{array}{c}0.281 \\
3\end{array}$ & 76.81 \\
\hline $\mathbf{1 0}$ & $\begin{array}{c}1.758 \\
2\end{array}$ & $\begin{array}{c}1.245 \\
0\end{array}$ & $\begin{array}{c}0.059 \\
0\end{array}$ & $\begin{array}{c}0.469 \\
0\end{array}$ & $\begin{array}{c}0.145 \\
7\end{array}$ & $\begin{array}{c}0.327 \\
0\end{array}$ & 78.28 \\
\hline
\end{tabular}

Next part discusses detailed explanation of the process of developing the artificial neural network model.

\section{DESIGN The ARTIFicial NeURAL NETWORK}

Depending on the preceding steps; the most effective FR that affect company financial performance were considered as dependent variables in the neural network model, while the performance index obtained from the fuzzy clustering process is the dependent variable in the model. Many software applications are used to simulate the behavior of ANN. The current research uses "Matlab" software to develop network model.According to "BrainMaker Professional", the number of chosen data to develop the network must be checked if it is enough or not, this step can be checked by using the next two guidelines:

- Guideline 1: Number of Training financial data

- Minimum Number of Training financial data $=2 *($ Inputs + Hidden + Outputs $)$

- Maximum Number of Training financial data $=10 *($ Inputs + Hidden + Outputs)

- Inputs $=6$ financial ratios.

- Outputs $=1$ Predicted financial company performance.

- Hidden: A hidden neuron in a hidden layer store the information needed for network to make predications. Guideline 2: Number of Hidden Neurons

- $\quad$ Number of Hidden Neurons $=($ Inputs + Outputs $) / 2=(6+1) / 2=4$ Neurons

Substituting the result of equation (9) in equations (8) and (7)

- Minimum Number of Training Facts $=2 *(6+4+1)=22$ financial data.

- Maximum Number of Training Facts $=10 *(6+4+1)=110$ financial data.

The number of the financial data that obtained after the fuzzy clustering process is sixty-eight. Therefore, this number is satisfactory because it is equal to the recommended minimum number that obtained from guideline 1 . These two guidelines can help in getting started with first network architecture. Then, after training and testing phases, the changes in the number of hidden layers and the number of hidden neurons will be performed in each layer guided by the percentage of error of the network until the best network is obtained (Yahia, 2011).

\section{XIX.}

Training THE NETWORK

All trial models experimented in this study was trained in supervised mode by a back propagation learning algorithm. Given data set is presented to the network as inputs, and the outputs were calculated. The differences between the calculated outputs and the actual outputs were then evaluated and used to adjust the networks weights to reduce the differences. Figure (5) shows the training process.

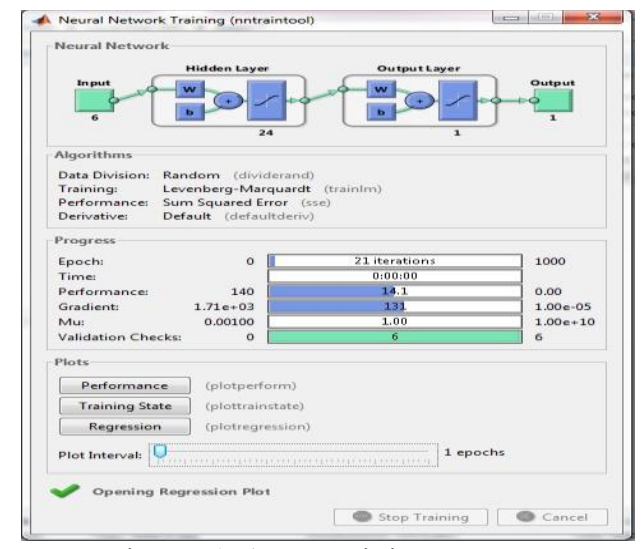

Figure 5: ANN training process

The back Propagation algorithm involves the gradual reduction of the error between model output and the target output.it develops the input to output mapping by minimizing a Root Mean Square error (RMS) which is expressed by the following equation (10) (Kohonen, 1988):

$\mathrm{RMS}=\sqrt{\frac{\sum_{\mathrm{t}=1}^{\mathrm{n}}\left(\mathrm{O}_{\mathrm{i}}-\mathrm{P}_{\mathrm{i}}\right)^{2}}{\mathrm{n}}}$ 
Where;

$\mathrm{O}_{\mathrm{i}}=$ the actual output related to the sample.

$\mathrm{P}_{\mathrm{i}}=$ the predicted output.

$\mathrm{n}=$ the number of samples to be evaluated in the training phase.

\section{The Best STRUCTURE Model OUTPUT}

The best structure model from the MATLAB program gives the predicted financial performance for any company by entering its financial ratios. Figure (5) shows the structure of the best model. MATLAB neural network model was considered as a package which the company owner can use it to evaluate his company financial performance.As a result, from training and testing phases the characteristics of the best modelare:

Input Layer with 6 neurons. One Hidden layers with 12 neurons. Output Layer with 1 neuron. Transfer Function: Tan sigmoid function.

Root mean Square Error $(\mathrm{RMSE})=1.409$

Max error $=6.65$

Max error $\%=11.40 \%$

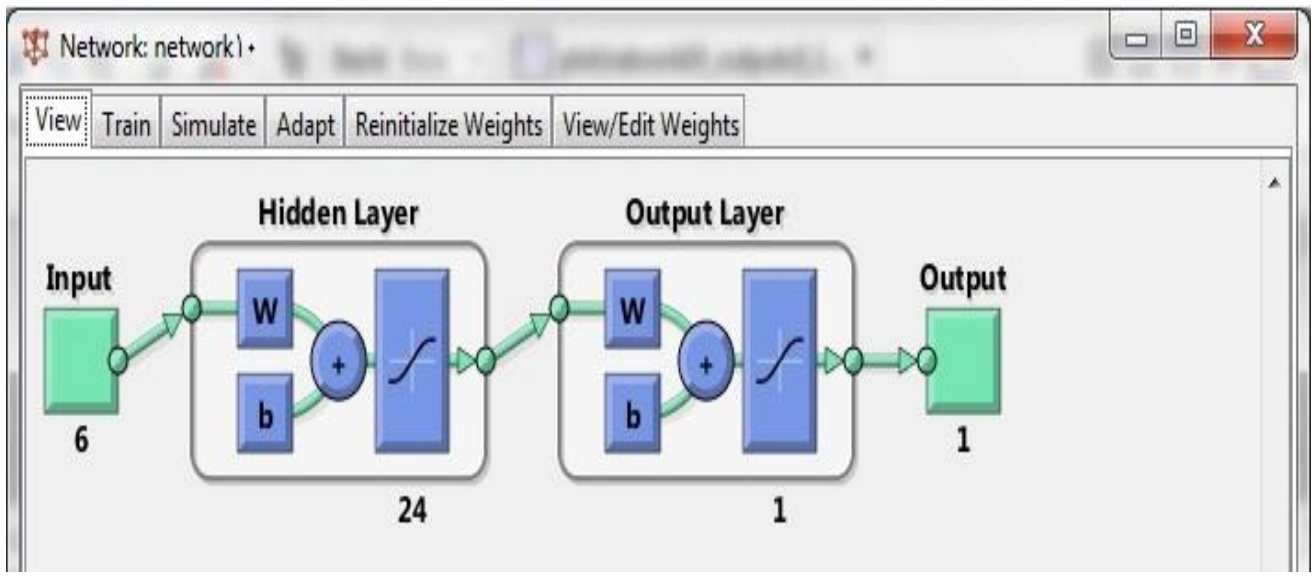

Figure (5) structure of the best model

Table (7) shows a sample of the target and predicted performance for 55 cases which MATLAB was trained, also shows the difference between the actual and predicted performance with its error percentage related to the actual performance.

Table (7): Simulating Data with the Best Model

\begin{tabular}{|c|c|c|c|c|}
\hline Case No. & $\begin{array}{c}\text { Target } \\
\text { performance }\end{array}$ & $\begin{array}{c}\text { Predicted } \\
\text { performance }\end{array}$ & $\begin{array}{c}\text { Absolute } \\
\text { Error }\end{array}$ & $\begin{array}{c}\text { Absolute } \\
\text { Error \% }\end{array}$ \\
\hline $\mathbf{1}$ & 85.4 & 85.30 & 0.10 & 0.1 \\
\hline $\mathbf{2}$ & 84.57 & 84.39 & 0.18 & 0.2 \\
\hline $\mathbf{3}$ & 86.15 & 84.61 & 1.54 & 1.8 \\
\hline $\mathbf{4}$ & 85.32 & 85.11 & 0.21 & 0.3 \\
\hline $\mathbf{5}$ & 85.8 & 85.03 & 0.77 & 0.9 \\
\hline $\mathbf{6}$ & 84.78 & 85.16 & 0.38 & 0.4 \\
\hline $\mathbf{7}$ & 80.79 & 81.66 & 0.87 & 1.1 \\
\hline $\mathbf{8}$ & 80.71 & 81.37 & 0.66 & 0.8 \\
\hline $\mathbf{9}$ & 76.81 & 76.50 & 0.31 & 0.4 \\
\hline $\mathbf{1 0}$ & 78.28 & 77.74 & 0.54 & 0.7 \\
\hline
\end{tabular}

XXI. VALIDATION OF THE ANN MODEL

The validation process is an important step to guarantee that the developed models best fit the available data. All models are tested statistically, logically, and practically to determine whether they are efficient in predicting real world results. The collected data are divided into two data sets, model building ( $80 \%$ of data set) and validation ( $20 \%$ of data set). The validation data set, which is selected randomly, is kept away while modeling the ANN. After building the model, the validation data set is utilized to test the ability of the developed model to predict the company FP. Table (8) presents the actual and predicted financial performance of the test sample. It shows that the difference between the predicted and actual performance ranges from $0 \%$ to 
11.69\%. The developed model is validated by comparing the predicted results with the actual values of the validation data set. From this results, it's cleared that the root mean square error (RMSE) for the validation sample equals 1.66 that can be considered as a good indication regarding the validity of the proposed neural network model.

Table (8): the actual and predicted performance of test sample

\begin{tabular}{|c|c|c|c|c|}
\hline $\begin{array}{c}\text { Case } \\
\text { NO. }\end{array}$ & $\begin{array}{c}\text { Actual } \\
\text { performance }\end{array}$ & $\begin{array}{c}\text { Predicted } \\
\text { Performance }\end{array}$ & $\begin{array}{c}\text { Absolute } \\
\text { Error }\end{array}$ & $\begin{array}{c}\text { Absolute Error } \\
\mathbf{\%}\end{array}$ \\
\hline $\mathbf{1}$ & 48.97 & 46.33 & 2.64 & 5.39 \\
\hline $\mathbf{2}$ & 20.92 & 21.19 & 0.27 & 1.29 \\
\hline $\mathbf{3}$ & 26.41 & 28.55 & 2.14 & 8.10 \\
\hline $\mathbf{4}$ & 21.04 & 23.07 & 2.03 & 9.65 \\
\hline $\mathbf{5}$ & 26.28 & 28.35 & 2.074 & 7.89 \\
\hline $\mathbf{6}$ & 23.09 & 24.69 & 1.597 & 6.92 \\
\hline $\mathbf{7}$ & 12.68 & 11.2 & 1.482 & 11.69 \\
\hline $\mathbf{8}$ & 10.09 & 8.98 & 1.11 & 11.00 \\
\hline $\mathbf{9}$ & 46 & 48.33 & 2.33 & 5.07 \\
\hline $\mathbf{1 0}$ & 49.01 & 47 & 2.01 & 4.10 \\
\hline $\mathbf{1 1}$ & 11.98 & 10.73 & 1.255 & 10.48 \\
\hline $\mathbf{1 2}$ & 12.11 & 10.86 & 1.246 & 10.29 \\
\hline $\mathbf{1 3}$ & 11.52 & 11.57 & 0.051 & 0.44 \\
\hline $\mathbf{1 4}$ & 12.02 & 12.43 & 0.406 & 3.38 \\
\hline
\end{tabular}

This demonstrates a high accuracy of the proposed model and its viability as a powerful tool for evaluating the financial performance of construction companies.

\section{CONCLUSION}

In construction companies, it is very important to measure performance due to the diversity and complexity of construction companies. The work presented shows that, a neurofuzzy model has been developed to evaluate the FP of residential construction companies. Two steps have been conducted using 86 financial data about 15 companies obtained from various construction companies in Egypt. The obtained data was prepared and extracted from financial documents as FR after analyzing data, first step was using FCM to classify the data and develop the performance index, then Utilizing ANN to develop the relation between performance index and FR variables. Finally, the developed model validated and give a satisfied result. The model can be used to evaluate FP of construction companies based on its FR.

The presented model has the following limitations:

1- Only six main FR are considered when developing the neurofuzzy model to evaluate the FP of a construction companies. Other ratios are not considered in this study.

2- The construction companies were selected for the study in a random manner so the characters of the companies are not considered in this study like company size or ranking.

3- The collected financial data for construction companies were collected for the time period 2000-2011.

The abovementioned limitations will be considered for future studies in order to improve the developed performance evaluation model.

\section{REFERENCES}

[1]. AbdElshakour, H., Al-Sulaihi, I., and Al-Gahtani, K. (2013) "Indicators for measuring performance of building construction companies in Kingdom of Saudi Arabia." Journal of King Saud University - Engineering Sciences Vol. 25, No. 2, pp. 125-134.

[2]. Alwakil, E. (2011) " Knowledge Discovery Based Simulation System in Construction" PhD thesis, CONCORDIA UNIVERSITY.

[3]. Ahiaga D., Tokede O., Smith S. and Wamuziri S. (2013) "A neuro-fuzzy hybrid model for predicting final cost of water infrastructure projects" ARCOM Conference, 2-4 September 2013, Researchers in Construction Management, 181-190.

[4]. Abdul Halim, M., Jaafar M., Osman O. and Haniff SH. (2012) "Financial Ratio Analysis: An Assessment of Malaysian Contracting Firms" Journal of Construction in Developing Countries, Vol. 17, No. 1, 71-78.

[5]. Adkins, T. (2006) "Case studies in Performance Management: A Guide from the Experts." John Wiley \& Sons, New Jersey, ISBN: 978-0-471-77659-8.

[6]. Altman, E. I., (1968) "Financial Ratios Analysis Discriminate Analysis and the Prediction of Corporate Bankrupt" , The Journal of Finance, Vol. 23, No. 4, pp. 589-609. 
[7]. Bataineh, K., and Saqer, M. (2011) "A Comparison Study between Various Fuzzy Clustering Algorithms" Jordan Journal of Mechanical and Industrial Engineering, Vol. 5 No.4.

[8]. Beaver, W. H., (1968) "Market Prices, Financial Ratios, and The Prediction of Failure", Journal Accounting Research, Vol. 6, No. 2, pp. 179-192.

[9]. Bezdek. J. C. (1981): "Pattern Recognition with Fuzzy Objective Function Algorithms", Plenum Press, New York.

[10]. Boussabaine, H. A. and Kaka, P. A. (1998), "A neural networks approach for cost flow forecasting." Construction Management and Economics, 16, 471-479.

[11]. Boussabaine, A. H. (2001). "Neuro-fuzzy modeling of construction projects' duration. I: Principles. Eng., Constr., Archit. Manage., Vol. 8, No. 2, pp. 104-113.

[12]. Dunn, J., C. (1973): "A Fuzzy Relative of the ISODATA Process and Its Use in Detecting Compact Well-Separated Clusters", Journal of Cybernetics 3: 32-57.

[13]. Dun \& Bradstreet (2001) "Fourteen Key Business Ratios Used by D\&B", [https://www.dnb.com/product/contract/ratiosP.htm].

[14]. Edmisteer R. (1972) "An Empirical Test of Financial Ratio Analysis for Small Business Failure Prediction", the Journal of Financial and Quantitative Analysis, Vol. 7, No. 2, pp. 1477-1493.

[15]. Elyamany, A.; Basha, I.; and Zayed, T. (2005). "A Performance Evaluating Model for Egyptian Construction Companies" Journal of Construction Engineering and Management, Vol. 133, No. 8, pp. 574-581.

[16]. Elyamany, Ahmed (2005) "Performance Evaluating Model for Construction Companies “, MSc Thesis, Zagazig University, Egypt.

[17]. Farghaly, k (2010) "Modeling the Financial Performance of Construction Companies, Using Artificial Neural Network", MSc Thesis, Alexandria University, Egypt.

[18]. Fuller, R. (1995) " Neural Fuzzy Systems", Abo Akademistryckeri, Abo, ESF Series A:443.

[19]. Fillipone, R. W. (1976) "A Statistical Analysis of Some Common Underwriting Measures Used By Contract Surety Underwriters", MSc thesis, School of Business Administration, Cleveland State University, Cleveland, Ohio.

[20]. Gallizo, JL, and Salvador, M, (2003) "Understanding the Behaviour of Financial Ratios: The Adjustment Process" Journal of Economics and Business, Elsevier, vol. 55, no. 3, pp. 267-283.

[21]. Georgy, M., Chang, L., and Zhang, L. (2005). "Prediction of Engineering Performance: A Neurofuzzy Approach." Journal of Construction Engineering and Management, Vol. 131, No. 5, pp. 548-557.

[22]. Goda A. (1999), "Assessment of Construction Contracting companies Performance in Egypt", Ph.D. Thesis, Faculty of Engineering. Zagazig University, Egypt.

[23]. Halpin, D. W., (1985), "Financial and Cost Concepts for Construction Management", John Wiley \& Sons Inc.

[24]. Jain, A., Jha, S. and Misra, S. (2008), " Modeling and Analysis of Concrete Slump Using Artificial Neural." J. Mat. In Civ. Engrg. Volume 20, Issue 9, pp. 628-633.

[25]. Jin, X. (2010) "Neurofuzzy Decision Support System for Efficient Risk Allocation in Public-Private Partnership Infrastructure Projects" Journal of Computing in Civil Engineering, Vol. 24, No. 6, pp. 525-538.

[26]. Kim, G.H., Yoon, J.E, Ana, S.H., Cho, H.H., Kang, K.I. (2004b), "Neural Network Model Incorporating a Genetic Algorithm in Estimating Construction Costs." Journal of Building and Environment, 39, 1333- 1340.

[27]. Kohonen, T. (1997) "An Introduction to Neural Computation", Neural Networks, Volume 1, Issue 1, 1988, pp. 3-16

[28]. Lam, K. C., Hu, T., Ng, S. T., Skitmore, M., and Cheung, S. O. (2001). "A fuzzy neural network approach for contractor prequalification." Construction Management and Economics, Vol. 19, No. 2, pp. 175-188.

[29]. Lee, M. (2006). "Risk Assessment of Drinking Water supply in Canada." MS Thesis, University of Guelph, Ontario.

[30]. Liu, M., and Ling, Y. Y. (2003). "Using fuzzy neural network approach to estimate contractors." Building Environment, Vol. 38, No. 11, pp. 1303-1308.

[31]. Mahmoud, M and Zayed, T. (2014). "Neurofuzzy-Based Productivity Prediction Model for Horizontal Directional Drilling." Journal of Pipeline Systems Engineering and Practice, Vol. 5, No. 3, pp. 1949-1204.

[32]. Maulenkamp, F. and Grima, M. A. (1999) "Application of neural networks for the prediction of the unconfined compressive strength (UCS) from Equotip hardness", International Journal of Rock Mechanics and Mining Sciences, Vol. 36, No. 1, pp. 29-39.

[33]. Mendel, M. (2001) "Uncertain rule-based fuzzy logic system: introduction and new directions". Practice Hall, New Jersey.

[34]. Mohamad, H.H., Ibrahim, A.H., Massoud, H.H. (2014) "Modelling the financial performance of construction companies using neural network via genetic algorithm”, Canadian Journal of Civil Engineering, Vol. 41, No. 11, pp. 945-954.

[35]. Moselhi, O., Hegazy, T. and Fazio, P. (1991). "Neural Networks as Tools in Construction" Journal of Construction Engineering and Management, Vol. 117, No. 4, pp. 606-625.

[36]. Moyer, R. (1977) "Forecasting Financial Failure: A Re-Examination." Financial Management, Vol. 6, No.1, pp. 1117.

[37]. Marzouk, M., \& Moselhi, O. (2004). "Fuzzy clustering model for estimating haulerse travel time. Journal of Construction Engineering and Management, 130, 878.

[38]. NCSS Statistical Software (2014) "NCSS Help" [https://www.NCSS.com]. Chapter 448.

[39]. Newton, G. W. (1994)." Financial accounting and reporting " fourth edition, Malibu publishing company, Inc., Westlake village.

[40]. Nitin Kumari et al(2013)," Comparison of ANNs, Fuzzy Logic and NeuroFuzzy Integrated Approach for Diagnosis of Coronary Heart Disease: A Survey Computing Vol.2 Issue. 6, June- 2013, pg. 216-224. 
[41]. Parvizsedghy, L. and Zayed, T. (2015). "Consequence of Failure: Neurofuzzy-Based Prediction Model for Gas Pipelines." J. Perform. Constr. Facil., 10.1061/(ASCE)CF.1943-5509.0000817, 04015073.

[42]. Rashidi, A., Jazebi, F., and Brilakis, I. (2011) "Neurofuzzy Genetic System for Selection of Construction Project Managers.” Journal of Construction Engineering and Management, Vol. 137, No. 1, pp. 17-29.

[43]. Ross., J. (2009) "Fuzzy logic with engineering applications" John Wiley \& Sons.

[44]. Russell J. S., and Zhai H. (1996) "Predicting Contractor Failure Using Stochastic Dynamics of Economic and Financial Variables", Journal of Construction Engineering and Management, Vol. 122, No. 2, pp. 183-191.

[45]. Tehrani, R., Mehragan, M., and Golkani M. R. (2012)"A Model for Evaluating Financial Performance of Companies by Data Envelopment Analysis" International Business Research, Vol. 5, No. 8.

[46]. Thippara, T. and Thaseepetch, T. (2012) "Application of Neuro-Fuzzy System to Evaluate Sustainability in Highway Design" International Journal of Modern Engineering Research, Vol. 2, No. 5, pp. 4153-4158.

[47]. Tokede O and Wamuziri S (2012) "Perceptions of fuzzy set theory in construction risk analysis" Edinburgh, UK, Association of Researchers in Construction Management,1197-1207.

[48]. Yalcin, N., Bayrakdaroglu, A., and Kahraman, C. (2012) "Application of fuzzy multi-criteria decision making methods for financial performance evaluation of Turkish manufacturing industries" Expert Systems with Applications, Vol. 39, No. 1, pp. 350-364.

[49]. Yahia, H. H. (2011). "Time Contingency Assessment in Construction Projects in Egypt using Artificial Neural Networks Mode." International Journal of Computer Science Issues, Vol. 8, Issue 4, No 2. Zadeh, L. (1992) "The role of fuzzy logic in modeling, identification and control" Modeling Identification, and control, Vol. 15, No 3, pp. 191-203.

[50]. Zaptron, S. (1999) "Neurofuzzy: A different type of Neural Nets." Retrieved from ZAPTRON Systems Inc., [http://www.zaptron.com/literature/neurofuzzy.htm]

[51]. Zayed, T., and Halpin, D. (2005). "Pile construction productivity assessment." Journal of Construction Engineering and Management, Vol. 131, No. 6, pp. 705-714. 